\title{
ORGANIZACÕES SOCIAIS E AGROECOLOGIA: CONSTRUÇÃO DE IDENTIDADES E TRANSFORMAÇÕES SOCIAIS
}

SOCIAL ORGANIZATIONS AND AGROECOLOGY: CONSTRUCTING IDENTITY AND SOCIAL TRANSFORMATION

\section{RESUMO}

No presente trabalho, procuramos discutir as transformações ocorridas no espaço da agricultura familiar pós-Revolução Verde, especialmente a partir do movimento contestatório engendrado por organizações sociais que defendem o ideário agroecológico. Inicialmente, procurou-se compreender como a identidade a e realidade social são construídas e reconstruídas socialmente. Utilizou-se uma abordagem fenomenológica para investigar como se dá a ruptura com a realidade convencional e a transição para a agroecologia. Com base nas evidências empíricas, é possível dizer que a agroecologia participa da ressignificação positiva da identidade social dos agricultores. Entretanto, o reconhecimento da nova identidade passa pelo questionamento da realidade dominante a partir de crises vividas pelos agricultores. Sua manutenção requer partilhá-la intersubjetivamente com um grupo ou organização.

\section{Márcio André Leal Bauer}

Professor do Departamento de Ciências Econômicas, Administrativas e Contábeis, Universidade Federal do Rio Grandee mbauer@vetorial.net

\section{Zilá Mesquita}

Professora e pesquisadora aposentada da Escola de Administração, Universidade Federal do Rio Grande do Sul

zilamesquita@yahoo.com.br

Recebido em 29.06.2006. Aprovado em 14.04.2008

Avaliado pelo sistema double blind review

Editor Científico: Rodrigo Bombonati

\begin{abstract}
In this work we seek to discuss the transformations that have occurred in family farming since the Green Revolution, especially since the protest movement that engendered the social organizations that defend the ideals of agroecology. Initially, we sought to understand how identity and social reality are constructed and reconstructed socially. A phenomenological approach was used to investigate how the break with conventional reality and the transition to agroecology occur. Based on empirical evidence we can say that agroecology helps provide a new and positive meaning to the social identity of farmers. However, recognition of the new identity involves questioning the dominant reality, starting with the crises experienced by farmers. Maintaining identity requires sharing it inter-subjectively with a group or organization.
\end{abstract}

PALAVRAS-CHAVE Identidade, realidade, organizações sociais, agroecologia, construcionismo.

KEYWORDS Identity, reality, social organizations, agroecology, social constructionism. 


\section{INTRODUÇÃO}

Este trabalho faz um estudo empírico da adoção de novas identidades a partir da transformação da realidade social. Em especial, analisa-se a transição da agricultura convencional para a ecológica, tentando compreender como se dá a ruptura com uma realidade admitida como natural e os reflexos dessa ruptura na reconstrução e ressignificação da identidade social de agricultores. Baseia-se em dois anos de pesquisa em organizações de agroecologia em duas regiões do Rio Grande do Sul: Zona Sul e Vale do Rio Pardo. Convencionou-se chamar de Zona Sul a área do Rio Grande do Sul que compreende os municípios de Canguçu, Morro Redondo, Pelotas, São Lourenço do Sul, Turuçu e Arroio do Padre. Por sua vez, o Vale do Rio Pardo compreende os municípios de Santa Cruz do Sul, Vale do Sol, Venâncio Aires e Vera Cruz. Essas regiões foram escolhidas porque apresentam inúmeras semelhanças entre si: seus municípios são áreas de imigração, de pequenas propriedades, de agricultura familiar e de produção ecológica atendidas pelas mesmas Organizações Não Governamentais (ONGs).

Durante o período da pesquisa foram estudados tanto os grupos, associações e cooperativas de agricultores que se dedicam ao cultivo de alimentos de forma ecológica, quanto as ONGs responsáveis pela assessoria aos produtores. O entrelaçamento dessas organizações produziu uma organização em rede, expressão de um movimento social embrionário centrado nos princípios da agroecologia.

De acordo com Darolt (2002), a agroecologia é uma das correntes da Agricultura Orgânica que endereça questões ligadas à justiça social. Almeida (2004) acredita que a agroecologia substituiu a noção-chave de tecnologia alternativa, incorporando idéias ambientais (ecológicas, preservacionistas e conservacionistas do meio ambiente) e sociais acerca da agricultura; seu escopo extrapola os limites do campo da agricultura. "[A agroecologia] tem se apoiado no uso potencial da diversidade social e dos sistemas agrícolas, especialmente aqueles que os agentes reconhecem como estando mais próximos dos 'modelos' camponês e indígena" (ALMEIDA, 2004, p. 89).

Na seção seguinte, são apresentados os conceitos centrais do trabalho - identidade e realidade - a partir de uma abordagem construcionista. A seguir, são descritos os procedimentos relativos à investigação realizada nas organizações agroecológicas. Na terceira seção, apresentam-se o contexto sócio-histórico e as evidências empíricas do estudo. A última seção é reservada para as conclusões e sugestões para direcionamentos futuros de pesquisa.

\section{REFERENCIAL TEÓRICO: A ABORDAGEM CONSTRUCIONISTA}

Na discussão teórica que se segue, os conceitos centrais deste trabalho - identidade e realidade social -são abordados de uma perspectiva construcionista, com raízes no pensamento de Marx (2005, p. 139) de que a sociedade "produz o homem enquanto homem", assim como é por ele produzida. Marx rejeita a idéia da sociedade como uma abstração, em antagonismo com o indivíduo, afirmando que o indivíduo é, antes de mais nada, um "ser social". Tal perspectiva ganhou notoriedade com o trabalho de Berger e Luckmann (1985), que reelaboraram a idéia marxista de que o pensamento humano funda-se na atividade humana (trabalho) e nas relações sociais por ela produzidas.

Para a sociologia bergeriana, o processo dialético fundamental da sociedade consiste em três momentos: exteriorização, objetivação e interiorização. "É através da exteriorização que a sociedade é um produto humano. É através da objetivação que a sociedade se torna uma realidade sui generis. É através da interiorização que o homem é um produto da sociedade" (BERGER, 1985, p. 15). O indivíduo que reflete sobre si próprio defronta-se então com duas realidades: uma subjetiva e outra objetiva (BERGER e LUCKMANN, 1985). Inicialmente tentaremos compreender a "realidade subjetiva" como o processo de formação da identidade do indivíduo ("si-mesmo"), o que é apenas um dos aspectos da realidade social, conforme a concepção original de Schutz (1995) que será abordada na seqüência.

\section{A Identidade}

Neste estudo, a identidade pode ser entendida de forma dialética. Há uma objetividade, que diz respeito às tipificações do senso comum atribuídas a pessoas, grupos ou organizações, com as quais o indivíduo pode identificar-se. Há também uma subjetividade, no tocante à tentativa do indivíduo em integrar essas identidades sociais em uma narrativa única e coerente com o si-mesmo.

Assim, a identidade pode ser entendida como uma construção que se dá em relação às identidades dos outros membros do seu grupo social. Ela é essencialmente uma estrutura social, o que torna impossível concebê-la fora da experiência social. Sua unidade e estrutura refletem a unidade e estrutura do processo social como um todo (MEAD, 1962, p. 164), estando sujeita às transformações ocorridas ao longo do processo de interação do indivíduo com os integrantes do seu grupo.

No caso da agricultura familiar ecológica na região es- 
tudada, isso se verifica à medida que os agricultores buscam grupos que estejam alinhados com suas identidades. A identificação faz com que a identidade do grupo seja incorporada à narrativa da identidade do indivíduo, para compor uma narrativa única. Assim, é possível encontrar agricultores que se identificam tanto com o grupo da igreja quanto com o ecológico, ou que afirmam ser o grupo ecológico, a associação e a cooperativa "a mesma coisa" (BAUER e MESQUITA, 2007).

É, pois, o conceito de identificação que permite tratar a identidade de maneira relacional, como um processo em andamento (HALL, 2000). A identificação é um processo que remete ao ato de identificar: marcar ou destacar algo. Significa, ainda, reconhecer uma marca em algo ou alguém. Associando identificação e identidade, pode-se dizer que identificar significa reconhecer uma marca que lembra determinada identidade. Já identificar-se significa reconhecer no outro uma marca que o indivíduo julga também possuir - e que o torna semelhante e pertencente a um mesmo grupo.

Essas marcas podem ser estigmas ou emblemas, que levam uma identidade social a ser exaltada ou escondida (CASTELLS, 1999). Isso introduz a questão da contrastividade, trabalhada por Oliveira (1976), e da relação, que pode ser também de dominação e poder. O olhar relacional significa reconhecer a importância do outro na composição do si-mesmo, pois é só através do diferente que a identidade pode ser percebida como singular (CUCHE, 1999, p. 183). Bourdieu (1996) afirma que há propriedades "ligadas à origem através do lugar de origem, bem como às demais marcas que lhe são correlatas, como por exemplo, o sotaque", que se transformam em estigmas ou emblemas; mostra ainda que "o móvel de todas essas lutas é o poder de impor uma visão do mundo social através dos princípios de divisão que, tão logo se impõem ao conjunto de um grupo, estabelecem o sentido e o consenso sobre o sentido, em particular sobre a identidade do grupo" (BOURDIEU, 1996, p. 108).

No contato com o outro, o diferente pode ser percebido como superior e a cultura do grupo pode ser desvalorizada, passando a ser omitida, negada e, por fim, esquecida. Esse é um processo que se verifica nas relações sociais entre o campo e a cidade e que tem levado o agricultor familiar a querer exibir um estilo de vida moderno percebido como único legítimo. Nesse caso, o elemento da cidade tem, nas palavras de Bourdieu (1996), o poder de instituir a representação do real, que por conseqüência pode fazer acontecer o que ela representa.

Por outro lado, a agroecologia quer atuar na reconstrução de identidades que levem a uma consciência identitá- ria e à participação coletiva, não podendo ser entendida somente como uma agricultura "que não utiliza agrotóxicos ou fertilizantes químicos de síntese em seu processo produtivo". Estes últimos elementos, isoladamente, poderiam caracterizar uma agricultura "pobre, desprotegi$\mathrm{da}$, cujos praticantes não têm ou não tiveram acesso aos insumos modernos" por impossibilidade econômica, falta de informação, ou mesmo de políticas públicas para tal fim (CAPORAL e COSTABEBER, 2004, p. 49).

Sob um enfoque relacional e situacional, existe uma identidade que é construída e reconstruída constantemente no interior das trocas sociais e que pode, sob certas circunstâncias, ser manejada, estratégica ou inconscientemente, para buscar reconhecimento e fugir de uma situação de preconceito (CUCHE, 1999). Isso pode levar não apenas a estratégias individuais de utilização de "marcas positivas", conforme nos aponta Goffman (1988, p. 67), mas também a ações coletivas. Nesse sentido, identidades coletivas podem ser compreendidas a partir das interações sociais e "da razão político-estratégica de atores sociais" (SANTOS, 1998, p. 151).

Adotando tais premissas, interpretou-se inicialmente a agroecologia como aquilo que Castells (1999, p. 24) chamou de uma "identidade de resistência", criada por atores que se encontravam em "posições/condições desvalorizadas e/ou estigmatizadas pela lógica da dominação, construindo, assim, trincheiras de resistência e sobrevivência com base em princípios diferentes dos que permeiam as instituições da sociedade". Essa identificação levaria os agricultores a aderirem à proposta da agroecologia, uma vez que traz uma conotação positiva e possibilita a filiação dos agricultores a essa forma de atividade rural, engajando-os em atividades coletivas.

$\mathrm{Na}$ análise dos dados empíricos, veremos que somente a identidade não dá conta da explicação do processo de transição de uma agricultura convencional para a ecológica. É preciso compreender como se constrói e se transforma a própria realidade objetiva.

\section{A construção e transformação da realidade}

Na perspectiva de Berger e Luckmann (1985), a realidade cotidiana parece já objetivada, ou seja, composta de "objetos" que foram designados como tais antes de nossa entrada em cena. É também uma realidade subjetiva que vai sendo construída à medida que somos socializados. Para Schutz (1995), essas realidades são, na verdade, uma só, ou seja, partes de um único "mundo da vida". Esse mundo é "apreendido" pelo indivíduo de forma subjetiva, "vivido" como um mundo social e "transmitido" de forma objetiva a seus sucessores. 
Inspirado nas idéias de William James, Schutz (1995, p. 197) construiu sua teoria sobre as múltiplas realidades, preferindo chamá-las de âmbitos finitos de sentido, por entender que somente dentro de uma realidade as experiências fazem sentido. Cada realidade pode então ser entendida como um conjunto de experiências que demonstram um "estilo cognitivo" específico, sendo que a realidade é constituída pelo "sentido das experiências" e não pela "estrutura ontológica dos objetos" (SCHUTZ, 1995, p. 303).

Para Schutz, existe uma realidade iminente, fruto da vida cotidiana, que se sobressai a outras realidades. Esse mundo é sustentado por um sistema de significatividades, constituído por um conjunto de experiências prévias que garantem ao indivíduo crenças sobre como a realidade funciona. À medida que estas crenças se verificam, ele adquire confiança e passa a não duvidar da realidade. Vistas sob o prisma de outra realidade, tais crenças e experiências pareceriam fictícias, incoerentes e incompatíveis, só sendo admitidas como reais mediante um "salto" ou "comoção", ou seja, mediante "uma modificação radical na tensão de nossa consciência, baseada em uma diferente atenção à vida"; isso obrigaria a "transcender os limites deste âmbito finito de sentido e transportar para outro o acento de realidade" (SCHUTZ, 1995, p. 216-217).

Tal "comoção" acontece, muitas vezes, a partir de experiências alheias ao "acervo de conhecimentos" que suscitam uma revisão das crenças anteriores até então consideradas como parte de uma realidade natural (SCHUTZ, 1995). São justamente essas as experiências novas que constituem um contrapeso a tudo aquilo a que nos habituamos, pois elas perturbam os aspectos rotineiros e tidos como certos da vida, frustram expectativas e originam surpresas, tornando-nos conscientes de determinados aspectos do mundo (HABERMAS, 1996).

Entretanto, é preciso ir além de uma perspectiva individual e especular sobre a possibilidade de realidades paralelas, partilhadas por comunidades de forma intersubjetiva. Berger e Luckmann (1985) chamam a atenção para o fato de que o surgimento da sociedade industrial e a formação de grandes centros urbanos (em que predominam a divisão do trabalho e a estratificação social) propiciaram uma situação altamente pluralista, com a possibilidade de existência de diversos "mundos", ou realidades paralelas. Entretanto, sempre existe uma realidade dominante, legitimada por um universo simbólico que tenta negar ou integrar as demais realidades, pois estas constituem "a mais aguda ameaça à existência naturalmente aceita e rotinizada da sociedade" (BERGER e LUCKMANN, 1985, p. 134).
Para sustentar tal realidade, seria necessário, na opinião dos autores, uma comunidade que a partilhasse, começando pela própria família e passando pelos demais grupos sociais que sejam significativos para o indivíduo. Importante também seria a separação, ao menos simbólica, entre os que partilham da nova realidade e aqueles que vivem a antiga realidade, levando a uma nova interpretação, por parte do indivíduo, de sua biografia.

Depreende-se, portanto, que o indivíduo interpreta suas vivências para definir quem é e para assumir uma identidade (subjetiva). A sociedade, por sua vez, oferece a ele elementos socialmente válidos e encarados como uma realidade objetiva, que é tida como certa e empresta sentido para essa identidade. Mas, como observa Spink e Frezza (2004), esse não é um modelo estático, pois está sujeito a rupturas que decorrem do enfrentamento do não familiar e possibilitam ressignificação e transformação social.

Apesar de se dizer tributária de Hegel e Marx, a dialética bergeriana não coloca o foco nessa transformação. Seu olhar é muito mais atento à positividade, à identidade e a recursividade da vida social, sendo este apenas um dos pólos da dialética. Como este trabalho procura analisar a transformação, deve-se explorar o pólo representado pelas crises e "rupturas", bem como as "mediações transformadoras", conforme aponta Mesquita (1995, p. 90), que levariam a uma nova consciência identitária e à transformação da realidade objetiva.

\section{ABORDAGEM METODOLÓGICA}

A análise empreendida utilizou o aporte teórico-metodológico da Fenomenologia. Na concepção de Husserl (2001), a fenomenologia é um método que tem como objetivo o retorno às "coisas mesmas", ou seja, retornar ao "mundo da vida". Esse não é o mundo das abstrações e idealizações, mas o mundo em que os atores vivem a sua vida cotidiana, em que inventam e reinventam suas práticas e atribuem sentido às suas ações.

A idéia fundamental da fenomenologia husserliana é a noção de "intencionalidade de consciência", ou seja, a consciência não existe por si só, mas é sempre consciência de algo. Dessa maneira, não se investigam objetos em si, mas a representação deles na consciência. A palavra intencionalidade, por sua vez, significa que as pessoas assumem esses objetos de diversas maneiras (intenções), que podem ser percepções do objeto real, lembranças, imagens criadas, julgamentos predicativos, julgamentos de valor etc. (HUSSERL, 2001). Esse objeto, embora tenha uma existência física e real, uma vez na consciência, 
não possui definição objetiva, pois as pessoas não têm objetos em suas consciências, mas "fenômenos", isto é, representações imaginárias do objeto real. É exatamente dessas representações do objeto na consciência que a fenomenologia busca extrair as essências.

Como exemplo, pode-se dizer que a agroecologia não se apresenta de forma objetiva, com seus princípios e preceitos, a todos os agricultores. Cada um a percebe como um fenômeno de sua consciência e participa dela com motivações diferentes, de acordo com sua trajetória e experiência. Isso não impede que tenhamos similaridades e regularidades intersubjetivas. Essas condições de "intersubjetividade" são também fundamentais para o método fenomenológico, pois, além de buscar por significados partilhados, o pesquisador pode lançar mão de sua própria subjetividade como um elemento de análise. Isso só é possível pelo fato de ele guardar em si a experiência do mundo e dos outros (HUSSERL, 2001). Diante disso, não é no objeto que se encontra a verdade e as evidências, mas no próprio sujeito.

A fenomenologia ainda se caracteriza por um exercício de romper com a atitude natural diante do mundo (HUSSERL, 2001; SCHUTZ, 1979, 1995). É preciso, portanto, realizar uma "redução fenomenológica" do mundo, ou seja, colocar entre parênteses não só o nosso conhecimento prático sobre ele, mas também as proposições de todas as ciências que se referem à sua existência (SCHUTZ, 1995, p. 115). Com a redução fenomenológica (epoqué), capta-se toda a experiência da consciência pela qual, e através da qual, o mundo existe (SCHUTZ, 1995).

Diante disso, buscou-se, na pesquisa de campo, cap- tar as vivências tanto dos sujeitos pesquisados quanto do pesquisador. $\mathrm{O}$ ato de pesquisar foi também um ato de interpretar as situações experienciadas de maneira intersubjetiva. Foram realizadas 19 entrevistas em profundidade, semi-estruturadas, com o objetivo de compreender um pouco da experiência vivida pelo agricultor na agricultura ecológica, seus motivos de ingresso, as circunstâncias em que isto se efetivou e as pertenças grupais definidoras da identidade social.

Foram entrevistados os presidentes das cooperativas e associações, integrantes dos conselhos de decisão da rede formada pelas ONGs e organizações dos agricultores; coordenadores de grupo; e participantes de grupos com diferentes tempos de adesão à produção ecológica. Buscou-se equilibrar a quantidade de entrevistados entre as organizações e regiões, porém a Zona Sul, em função do número de organizações e grupos, foi a região com o maior número de entrevistados, conforme as seguintes tabelas.

A maioria das entrevistas foi feita com a utilização de gravador, para não se perder algum elemento essencial, uma vez que uma simples palavra pode representar a indicação de uma essência (SANDERS, 1982). Na análise das falas, embora o próprio roteiro da entrevista já apresentasse uma sequência lógica e um bom número de categorias pré-ordenadas, outras tantas apareceram, com importância igual ou superior. Buscou-se, a partir daí, estabelecer relações fundamentais entre elas, ou seja: de ligação, de dependência, de causalidade etc. (SPIEGELBERG segundo BRUYN, 1972). Dispondo de roteiro de entrevista e de um gravador, os encontros trouxeram mais informações que o esperado, uma vez que os agricultores paravam e

Tabela 1 - Número de entrevistados por organização e região

\begin{tabular}{|l|c|c|}
\hline \multicolumn{1}{|c|}{ ORGANIZAÇÃO } & N $^{0}$ DE ENTREVISTADOS & REGIÃO \\
\hline Cooperativa Sul Ecológica & 7 & Zona Sul \\
\hline Cooperativa Arpa-Sul & 5 & Zona Sul \\
\hline Cooperativa Ecovale & 7 & Vale do Rio Pardo \\
\hline TOTAL & 19 & \\
\hline
\end{tabular}

Tabela 2 - Número de entrevistados por grupo e município

\begin{tabular}{|l|c|c|c|c|c|}
\hline \multicolumn{1}{|c|}{ MUNICÍPIO } & PELOTAS & CANGUÇU & MORRO REDONDO & CANGUÇU & TOTAL \\
\hline Grupo & A & B & C & D & \\
\hline $\mathrm{N}^{0}$ entrevistas & 1 & 1 & 1 & 2 & 5 \\
\hline
\end{tabular}


dedicavam o tempo que fosse necessário, reforçando que a noção de tempo e de trabalho para eles é bem diferente da urbana.

Foram realizadas: visitas às propriedades, em que se observou o cotidiano dos agricultores, suas relações familiares, seus conflitos e projetos; observação sistemática, conforme apontam Selltiz e outros (1965), nas feiras ecológicas, visualizando-se as relações econômicas e sociais entre produtores e consumidores; participação em seminários, reuniões e congressos, o que propiciou a observação das relações entre os diversos públicos estudados; e acompanhamento de visitas técnicas das ONGs de assessoria a propriedades de agricultores familiares. Manteve-se um contato mais freqüente com três técnicos das ONGs de assessoria (CPT e CAPA) e com quatro agricultores que ocupavam posição de liderança em suas organizações (cooperativas e associações de agricultura ecológica). Analisaram-se publicações da rede, jornais internos das ONGs e algumas monografias de seus integrantes.

\section{ANÁLISE}

Embora algumas vertentes preconizem que os estudos baseados na fenomenologia não devem ter hipóteses prévias, ou teorias de base, isso é muito difícil. Se a consciência é sempre intencional, conforme aponta Husserl (2001), não se parte para o campo sem uma consciência prévia do que se está estudando, logo, sem uma hipótese ou teoria, que explique o que se observa. Sendo assim, na presente análise, procurou-se adotar uma orientação dialético-hermenêutica, a qual considera dois níveis de interpretação: o primeiro está relacionado com o contexto sócio-histórico do qual faz parte o grupo a ser estudado; o segundo baseia-se no encontro com os fatos surgidos na investigação - comunicações individuais, observação de condutas e costumes, análise das instituições e cerimônias etc. (MINAYO, 1999).

\section{Contexto sócio-histórico}

Desde os tempos da imigração ocorrida no Sul do país, coube à agricultura familiar um importante papel na produção de alimentos para o consumo interno. No entanto, ela permaneceu por muito tempo distante das políticas agrícolas do governo, voltadas, sobretudo, para a geração de divisas através da exportação.

As transformações na economia nacional do pós-guerra exerceram sobre a agricultura familiar um forte impacto. No plano internacional, estava em curso a chamada "Revolução Verde", que tomava por base as formas de produção capitalistas aplicadas à indústria e as transportava para a agricultura. Esse modelo de acumulação agroindustrial estava baseado "na convergência de tecnologias mecânicas e agroquímicas e na multiplicação de inovações biogenéticas" (POBREZA RURAL, 1998, p. 43). Tal processo ia ao encontro das necessidades nacionais de aumento de produtividade no campo, seja para $o$ atendimento da indústria interna, seja para o aumento das exportações.

O governo brasileiro, sobretudo nos anos de $1960 \mathrm{e}$ 1970, começa a incentivar a modernização da agricultu-

Tabela 3 - Número de entrevistados por grupo e município

\begin{tabular}{|l|c|c|c|c|c|}
\hline \multicolumn{1}{|c|}{ MUNICÍPIO } & CANGUÇU & TURUÇU & ARROIO DO PADRE & SÃO LOURENÇO & TOTAL \\
\hline Grupo & E & F & G & H & \\
\hline N $^{0}$ entrevistas & 2 & 2 & 2 & 1 & 7 \\
\hline
\end{tabular}

Tabela 4 - Número de entrevistados por grupo e município

\begin{tabular}{|l|c|c|c|c|c|}
\hline \multicolumn{1}{|c|}{ CIDADE } & SANTA CRUZ & VERA CRUZ & VALE DO SOL & VENÂNCIO AIRES & TOTAL \\
\hline Grupo & $\mathrm{I}$ & $\mathrm{J}$ & $\mathrm{L}$ & $\mathrm{M}$ & \\
\hline $\mathrm{N}^{0}$ entrevistas & 2 & 2 & 1 & 2 & 7 \\
\hline
\end{tabular}


ra, e isso passa por três movimentos: a transformação da base tecnológica através do estímulo à mecanização; a incorporação de novas variedades de plantas e aumento de insumos químicos; e a disponibilidade de crédito agrícola através do Sistema Nacional de Crédito Agrícola (POBREZA RURAL, 1998). O aumento da "produtividade" (ou da produção) passava obrigatoriamente pelo monocultivo, o que permitia a introdução de máquinas modernas no campo, sendo sua aquisição incentivada através de condições "vantajosas" de financiamento.

É possível afirmar que a "Revolução Verde" foi uma revolução silenciosa que introduziu, no universo da agricultura familiar, uma nova realidade social, com a substituição de parte do conhecimento tradicional por um científico e instrumental, que até então não se legitimara, por falta de condições objetivas. De um lado, havia convergência de interesses por parte dos agentes. De outro, instrumentos adequados para a sua instituição (tecnologia, crédito e assistência técnica). Os agricultores, no entanto, pareciam não perceber os impactos sociais e culturais que essa revolução trazia.

A despeito dessa modernização no campo, surgiram organizações ligadas a um movimento de contestação das formas convencionais de agricultura. Elas ganharam força a partir da "abertura democrática" e passaram a lutar pela transformação das práticas ditas modernas, mas que tiveram como conseqüência o êxodo rural, a exclusão social e o aumento das desigualdades (ALMEIDA, 1999). A gênese desse movimento pode ser encontrada na convergência de diversas ações empreendidas a partir do final da década de 1970 que foram denominadas "agricultura alternativa". Nesse período, começa um trabalho militante empreendido por setores progressistas das igrejas Católica - através da Comissão Pastoral da Terra (CPT) e da Evangélica Luterana (IECLB) - através do CAPA (Centro de Apoio ao Pequeno Agricultor), que passam a marcar sua presença junto aos agricultores familiares e àqueles oriundos do êxodo rural.

Surge uma visão "eco-libertária", que, segundo Almeida (1999, p. 92-93), tem como idéias centrais "a descentralização da economia, do poder e do espaço social", alinhadas aos ideais de justiça social e respeito ao meio ambiente e difundidas pelo nome de "agroecologia" (DAROLT, 2002). As ONGs passam então a assumir o termo agroecologia e a trabalhar seus princípios, junto aos agricultores familiares, por considerarem que exprimem "novas aspirações, novas formas de sociabilidade, uma vontade de promover outros modos de desenvolvimento econômico e social que seriam mais 'controláveis' e aceitos, porque estão espacialmente circunscritos, cultural e tecnicamente fundados na 'experiência do tempo"' (ALMEIDA, 2004 p. 89). Essa ancoragem subjetiva (identidade) diante de novas relações sociais objetivas (realidade) é que nos interessa no presente trabalho.

\section{Investigação Empírica}

Antes de realizar as entrevistas com os agricultores, sabia-se da existência informal de um movimento agroecológico em gestação, liderado por algumas ONGs, que estavam articulando-se em uma rede formal, conforme apontam Mesquita e Bauer (2004). Seus princípios e objetivos, em grande parte, espelhavam os princípios da agroecologia. Isso representaria a identidade objetiva desse movimento, como pode ser observado em um de seus documentos:

Nós acreditamos que os aspectos inerentes à agroecologia, a saber: proteção do ambiente, justiça e inclusão social, viabilização econômica, adaptação cultural e tecnológica que visem à construção de políticas públicas - devem ser analisados em conjunto com parâmetros semelhantes, ou seja, a questão ambiental é tão importante quanto a social, a cultural quanto a tecnológica, a econômica quanto a política e vice-versa. (REDE ECOVIDA, 2000)

Seguindo a argumentação de Castells (1999), acreditava-se que esses princípios fossem capazes de criar uma identidade social forte, formando um grupo bastante homogêneo e coeso em torno de um ideal. Isso ocorreria na passagem de uma identidade inicial "de resistência" para outra "de projeto", sendo esta última uma construção em que os atores, utilizando-se de qualquer tipo de material cultural, buscam redefinir sua posição na sociedade, bem como a transformação da estrutura social.

A análise inicial da pesquisa privilegiou o contato com os "agentes", mostrando que havia um movimento que se contrapunha à produção convencional. Esses ideais revelados nos depoimentos iniciais dos integrantes dessas organizações -, partilhados pela maioria das ONGs e trabalhados com os agricultores familiares, indicavam que realmente haveria uma união identitária em torno de um projeto comum, minimizando as diferenças entre seus participantes. A participação deles em um grupo seria o primeiro passo para que esse projeto se transformasse em uma identidade social. Isso porque, para receber assistência técnica de uma ONG e, posteriormente, comercializar em uma feira ecológica, o agricultor deveria pertencer a um grupo ecológico.

Nesse grupo, formado basicamente pelas comunidades locais em que os agricultores estão inseridos, ocorrem 
tanto o processo instrucional por parte das ONGs quanto as interações com outros agricultores, o que o leva a ser considerado como a própria extensão da família. A agroecologia é introduzida pelos agentes como parte de um resgate de práticas dos antepassados, ancorando o projeto não só em bases racionais, mas também em um elemento emocional com sentido para o agricultor.

Contudo, ao dar voz aos agricultores da base, a adesão à agroecologia pela identidade foi suplantada por uma nova visão que emergiu de suas falas. Os relatos mostraram que o aspecto distintivo existe mais facilmente dentro das próprias organizações de agroecologia, entre agricultores ou grupos ecológicos com posturas diferentes (alguns mais individualistas, por exemplo), do que entre agricultores ecologistas e convencionais. Embora as ONGs pretendam construir o consenso identitário em torno de uma proposta, em muitas situações cotidianas as diferenças regionais, étnicas e individuais emergiram: "Eles têm a postura de tirar o máximo"; "O nosso grupo é mais forte"; "Nós ocupamos espaço e agora eles querem reconquistar o espaço"; "Eu não me importo com o que os outros pensam [...], isso aí cada um tem que se virar". Essas falas, extraídas posteriormente de reuniões de grupo e em observações nas feiras, revelaram que, dentro de uma mesma organização de agroecologia, há contrastividade e individualismo.

Já em relação aos agricultores convencionais, a maioria dos ecologistas os percebe com um olhar bastante compreensivo, afinal são todos da mesma comunidade e, em última instância, são todos agricultores familiares, até mesmo amigos e parentes. Isso denota uma solidariedade identitária entre os agricultores ecológicos e convencionais, como revela a fala de um agricultor de Vera Cruz: "Eles vão ter que mudar um dia também, porque, se continuarem desse jeito, vão morrer [...]. É produto pesado que vai ali nas hortaliças convencionais e nas outras produções em geral."

O fato de não perceberem um "inimigo comum", aparentemente, impede a assunção de uma identidade coletiva por parte dos agricultores que estão longe das instâncias de decisão de suas organizações. Mesmo que tal identidade seja assumida pelas ONGs e lideranças dos agricultores, elas muitas vezes não conseguem transmiti-la de forma objetiva que faça sentido aos demais agricultores. Esses precisam passar por um processo lento de transformação, muitas vezes atropelado pela necessidade de sobrevivência.

A (falta de) consciência acerca do projeto agroecológico reflete-se na identificação que os agricultores têm de suas organizações. O exemplo claro é o da rede acima referida.
Ela é percebida por suas lideranças (aqueles que têm um bom tempo de participação e que fazem parte de algum conselho) como "uma organização de várias organizações de agricultores, de assessorias" para "unir todos os esforços nos três Estados, mostrar a força da agroecologia". Contudo, junto aos agricultores da base, a Rede é tida como uma organização externa que tem apenas o objetivo de certificar os produtos ecológicos. Questionados sobre sua participação na rede, alguns agricultores responderam: "Eu não sei bem, mas acho que participo"; "Rede do quê? Não, acho que não".

Em geral, os agricultores que apresentam maior consciência dos princípios e práticas da agroecologia são aqueles que têm participação mais ativa, fazendo parte de grupos que são espaços de discussão. Mas, se a participação se dá em função da consciência, o que leva então a essa tomada de consciência?

Isso nos fez buscar outro significado para a agroecologia, que transcendesse o de um grupo, movimento ou organização que possui uma identidade objetiva. Ou mesmo de uma nova identidade social partilhada pelos agricultores. Deixando suspensas as justificativas atribuídas por aqueles agricultores mais conscientes e pelos agentes das ONGs para a participação, buscaram-se os motivos e razões subjacentes à participação e à adesão dos agricultores em geral.

Para tanto, utilizou-se a distinção fundamental feita por Schutz $(1972,1995)$ acerca das classes de motivos que orientam a ação humana. Enquanto a primeira classe de motivos (motivos para) significa "o estado de coisas", o objetivo que se quer alcançar mediante a ação empreendida, a segunda classe (motivos por que) "se refere às experiências passadas", que levaram a tal ação, ou seja, os motivos genuínos da ação (SCHUTZ, 1972, 1995, p. 50). Os "motivos por que" buscam motivações relativas ao contexto, ou seja, àquelas situações da vida dos agricultores que os levaram a ingressar na agroecologia. Essas motivações foram buscadas a partir do relato de sua trajetória na agroecologia.

De ordem subjetiva, a experiência individual suscita a reflexão do agricultor. É essa espécie de "comoção", ou choque, que provoca a mudança de realidade, ocorrendo na vida da maioria dos agricultores, geralmente, a partir da doença em decorrência da utilização de agroquímicos no cultivo convencional, rompendo com a atitude natural. "Tenho lembrança de vários problemas de saúde que se teve e foi acusado o uso do defensivo. [...] Minha mulher teve dois abortos e os médicos atestaram que foi de usar [...]." (agricultor de Canguçu)

No entanto, é preciso extrair da doença ou da crise um 
significado diferente; caso contrário, tal experiência será traduzida dentro do universo simbólico dominante:

Chegava em casa e eu queria mudar na mesma hora porque enxergar aqueles vídeo com aqueles problema que dava de saúde e aí trabalhar no meio daqueles fumo [...] no meio de veneno [...]. Aí eu tinha os filhos pequenos ainda, $[\ldots]$ e trabalhando nessas coisas aí. E eu queria mudar logo porque uma mãe sempre quer ver o melhor pros filhos [...]. (agricultora de Morro Redondo)

Essa experiência leva à tomada de consciência de sua finitude, enquanto indivíduo isolado, em direção a outros cursos de ação, especialmente coletivos. Diante disso, o ingresso na agroecologia, embora possa ser incentivado por fatores externos (por exemplo: cursos e palestras ministrados pelas ONGs), requer a experiência subjetiva do indivíduo. A partir desse ponto é que as metodologias das ONGs são responsáveis pelo fomento à união dos agricultores em grupos.

O grupo transmite um senso de realidade, devido às experiências comuns dos participantes. Mesmo depois da mudança, a presença e o incentivo das ONGs são fundamentais, principalmente, na fase inicial, em que existe a maior probabilidade de abandono. Além disso, existe o incentivo dos próprios agricultores que já vivenciam essa realidade, muitos deles são vizinhos e familiares, outros são agricultores experientes que servem de referência na agroecologia.

A partir daí o agricultor passa a ter um novo "estilo cognitivo", ou seja, passa a conhecer o mundo e as relações de forma diferenciada. Sua identidade (si-mesmo) passa então a ter um novo significado, fruto muitas vezes de uma nova relação de comercialização que privilegia o contato direto com consumidores nas feiras ecológicas em centros urbanos. Chega-se aos consumidores dos produtos com os quais $o$ agricultor tem um encontro face a face nas feiras:

Não tem aquela visão assim que tu produziu, aí encosta um caminhão aqui no teu terreiro e carregou tua produção e tá; "daí tal dia eu te pago", né? [...] E na feira não, tu vai lá, chega lá, conversa com o consumidor, explica como é que é produzido, por que o produto tá feio, "ah choveu demais", ou "teve geada" ou "tá seco"; e com o tempo o consumidor já vai entendendo (agricultor de Turuçu).

Esse contato entre produtores e consumidores cria laços de amizade e estabelece uma relação de confiança. O agricultor percebe a importância do seu trabalho e torna-se cada vez mais sensível em relação à saúde dos consumidores, o que serve de reforço para não mais voltar a utilizar insumos químicos em suas plantações. O contato com um público que valoriza o seu trabalho faz com que ele se valorize e tenha orgulho de sua atividade, passando a usar identificadores (crachás, camisetas e bonés) que afirmam sua condição de produtores ecológicos: o que era estigma passa a ser emblema.

O modo de ver o colono, com o nosso tipo de trabalho [o ecológico] ele tá mudando. Antigamente eles viam um agricultor passar na rua e diziam "lá vai o colono". Porque sempre tem um meio diferente de andar, um meio diferente de se comunicar, de caminhar. Hoje já não, hoje a gente já tem uma amizade com esse pessoal da... com os consumidores daqui né, então a gente já é visto de outra maneira (agricultor de Pelotas).

Embora no meio rural ser chamado de colono pelos pares possa ter uma conotação positiva - a de "uma pessoa que vive da agricultura" e que "trabalha, cultiva e reside dentro do meio rural" (agricultor de Pelotas) -, na cidade ela é uma identidade estigmatizada, em que o "colono" é visto como símbolo do atraso. É ser "grosso do pé rachado; sem instrução nenhuma: um burro". Esse estigma pode ser um dos fatores que têm levado inúmeros jovens do campo ao êxodo e a buscar na cidade uma outra identidade, negando o projeto idealizado por seus pais. Ele quer, talvez, poder "andar rua afora e não ser visto de longe: aquele lá é um colono." (agricultora de Canguçu)

Portanto, além de um espaço de comercialização, a feira serve como mediador para a percepção do significado positivo da vida no campo. A identidade de agricultor começa a ganhar outro significado, mesmo com poucas mudanças objetivas em seu conteúdo. O que parece ter havido é uma nova compreensão da realidade, por parte do próprio agricultor, após um contato com um público que admira o seu modo de viver.

Eu vejo hoje que tá bem valorizado, mas há uns anos atrás era diferente. [...] Até quando entrava numa loja assim, pra atender, a gente via, né, que às vezes até os próprios funcionários se olhavam e aí conversavam que o pessoal era da colônia.... Hoje não, hoje eles vêm atender e fazem questão. Até sobre a agroecologia mesmo, comigo já aconteceu em várias lojas de eu ir e entrar em assunto assim e aí, no final da conversa, eles dá parabéns e que continue esse serviço. (agricultora de Morro Redondo)

Esse senso de realidade é reforçado pela coerência entre todas as experiências vividas, o que permite ao agricultor 
lutar pela manutenção de tais práticas e contra a introdução de outras, vistas como incoerentes (mesmo que estas práticas sejam as práticas cotidianas tidas como inquestionáveis pelos demais). A sua "atenção à vida" se dá de forma diferenciada ao considerar elementos não avaliados pela realidade da agricultura convencional, tais como a saúde, o meio ambiente e a participação política.

Essa maior atenção remete a uma perspectiva temporal também diferenciada, em que o imediatismo deve ser substituído por uma perspectiva de longo prazo, devido ao tempo de adaptação requerido pelo cultivo ecológico (de três a cinco anos, segundo apontam técnicos e agricultores). Um agricultor de Pelotas declara que "é um dos problemas mais sérios que se tem. Porque a maioria é imediatista, quer o dinheiro rápido e nesse tipo de trabalho não é isso aî".

Porém, nem todos os agricultores que permanecem se enquadram nessa construção de "tipo ideal", o que leva à existência paralela de grupos ecológicos - ou mesmo agricultores dentro de grupos - que se situam em diferentes níveis de realidade. Enquanto uns "vivem" plenamente os ideais da agroecologia, outros ainda estão atrelados à realidade convencional, não reconhecendo a agroecologia como uma realidade, mas como uma tecnologia de produção, ou como um nicho de mercado, o que os faz manter paralelamente produtos convencionais e ecológicos.

Esse é o caso do plantio de fumo, exemplo típico da agricultura convencional, que tem seduzido muitos agricultores, devido aos diversos incentivos financeiros concedidos pelas empresas fumageiras. Além disso, existe a pressão social dos parentes e vizinhos, que passam a exibir símbolos de uma melhoria do padrão de vida (um carro melhor, um trator, uma nova casa ou estufa).

Aqueles que não pensam em parar com o plantio de fumo acreditam que ele dá mais dinheiro e é bem mais prático, pois se planta um só produto. Para um agricultor de Turuçu, "o cara tá plantando fumo lá, o cara planta 50,80 mil pés de fumo, pelo dinheiro que dá aquilo. [...] Vai comparar com isso aqui [o ecológico], não tem nem comparação. E tu planta uma coisa só e não te incomoda com outras coisinhas, né?"

Em contrapartida, tem-se a visão daqueles que deixaram de produzir fumo e hoje dedicam-se somente à produção ecológica. Segundo um agricultor de Canguçu,

a maioria dos agricultores estão partindo pra plantação de fumo, que financeiramente é um negócio melhor e que me preocupa, né? Porque o fumo além dele não gerar comida, ele vai provocar desmatamento, mexe no meio ambiente.
A questão dos venenos que são usados no fumo também. [...] E o fumo, assim é uma coisa que tu é dependente de uma indústria, de uma multinacional, tu nunca sabe quanto tempo eles vão se manter nessa região.

O agricultor geralmente começa plantando pouca quantidade. Por ser um cultivo que, embora dê um bom ganho financeiro, exige muito trabalho em uma época do ano, a tendência é que o agricultor vá reduzindo os outros cultivos e venda os animais para investir tudo em fumo. Com o passar do tempo, o agricultor "perde o jeito" de plantar outros produtos e acaba tendo de comprar tudo de fora. "É triste, mas tem lugar na colônia que não se planta um pé de alface e o frango que se come é o Pena Branca congelado" (depoimento do técnico de uma ONG).

No plantio de fumo, a perspectiva temporal passa a ser ditada pela indústria. Os critérios de classificação dos produtos, antes de domínio absoluto do agricultor, passam a ser dos técnicos da empresa. Os insumos químicos utilizados são comprados em um pacote fechado da indústria e aplicados de acordo com as suas prescrições. Passam de produtores a trabalhadores rurais, sem direitos e sem qualquer controle sobre os meios de produção. Geralmente, os agricultores fazem investimentos em máquinas e na propriedade e precisam pagar os financiamentos, daí a necessidade de plantar mais e cultivar outros produtos convencionais em grande escala.

Nesse sentido, um agricultor de Turuçu afirma que "tem que se virar porque a gente faz dívida, faz dívida, então pra pagar a dívida tem que correr atrás. Comprei trator [...] e o cara compra tudo financiado".

As relações entre vizinhos são muito valorizadas dentro da agricultura familiar. Embora com o cultivo do fumo isso esteja mudando, ainda são bastante comuns as chamadas "trocas de serviços" e as visitas. Diante disso, o não-reconhecimento da realidade da agroecologia como legítima, por parte dos produtores convencionais - o que fica evidenciado no deboche e na incompreensão -, leva os agricultores ecológicos a serem vistos e tratados como "loucos", exercendo considerável pressão para o abandono dos principiantes, principalmente, em uma fase em que os resultados ainda são pequenos e o grupo ecológico ainda não se consolidou. Passado o período inicial, os agricultores ecológicos é que parecem exercer uma pressão sobre seus vizinhos, conforme depoimento abaixo:

A gente ouviu muitas críticas e muitos me gozaram e eu tive que discutir com eles até. Até domingo jogando carta! [...] E até com meus caminhoneiros que tinha lá eu discutia com eles. [...] agora tão começando, como eu 
falei do agricultor [...], que é um vizinho que nunca debochou de mim, mas ele ficou meio quieto. [...] Mas esse ano ele já começou, plantou quinze sacos já de batata ecológica, plantou feijão ecológico, mas não junto comigo [no grupo], ele tá junto com a cooperativa. (agricultor de São Lourenço)

Contudo, o caráter "real" da agroecologia começa a ser mais fortemente questionado à medida que, na própria família, encontra resistência e oposição. É ela, talvez, o elemento mais importante, sendo responsável pela permanência ou mudança de realidade, pois a participação é sempre decidida em conjunto. Isso leva os agricultores a afirmar que nos casos em que a família participa do grupo ecológico, e discute em conjunto as idéias, parece não haver problemas. No centro dessa questão está o fator econômico, ou a grande expectativa em torno dos rendimentos da produção e da comercialização direta por parte de um dos membros da família. Para um agricultor de Arroio do Padre, "até que no início se tu agarrava aí plantava aquele tu tinha comércio, né? Como na feira, porque as feiras eram boas no início. Então aquilo ali é o que dava assim uma alegria".

As constantes dificuldades, tanto ambientais quanto estruturais, forçam o agricultor e sua família a pensarem no curto prazo, na sobrevivência. Isso faz com que muitos tenham de buscar outras formas de cultivo para atender às "necessidades" imediatas, levando ao abandono gradual da agroecologia e reduzindo o cultivo ao nível da subsistência. Vale dizer que tais observações foram corroboradas, tanto pelos técnicos das ONGs quanto pelos agricultores, em um seminário de devolução dos dados da pesquisa.

\section{CONCLUSÃO}

O presente trabalho buscou discutir as transformações ocorridas no espaço da agricultura familiar pós- Revolução Verde. No plano da identidade, como se observou, essa revolução, por mais silenciosa que possa ter sido, não deixou de ser violenta, especialmente para a agricultura familiar, em que práticas tradicionais tidas como "atrasadas" foram substituídas por outras consideradas por muitos governos e órgãos de assessoria e pesquisa como sendo de vanguarda.

Atualmente, muitas dessas práticas são reintroduzidas através de um movimento social contestatório, engendrado por organizações sociais (ONGs e organizações dos agricultores) que defendem o ideário agroecológico. São apresentadas na forma de uma nova identidade a ser assumida pelo agricultor. Entretanto, toda e qualquer identidade requer consciência. O que se pergunta é: existiria tal consciência de forma ampla na agroecologia?

Viu-se no presente trabalho que a agroecologia, muito embora possa ser vista como um projeto alternativo, articulado e incentivado por organizações que contestam o atual modelo de agricultura convencional, só pode ser aceita pelos agricultores na forma de uma realidade coerente e legítima. Para o seu reconhecimento, esta realidade necessita de um choque no curso normal dos acontecimentos, que suscite uma revisão das crenças anteriores. Já para manter essa realidade, no entanto, a simples tomada de consciência por parte do agricultor não é suficiente. É necessária a pertença a um grupo ou organização que permita ao agricultor perceber a agroecologia como socialmente válida, como uma realidade possível. A teia de organizações que se estabelece no universo pesquisado é altamente positiva nesse sentido. Grupos, associações, cooperativas e ONGs associam-se em uma rede que permite transcender a idéia de organização em seu sentido estático e externo, bem como em um sentido puramente econômico, percebendo-a como intersubjetividade e processo. Processo esse que é também político, pois envolve uma luta social por projetos distintos para a sociedade, uma vez que não é possível assumir uma identidade sem a transformação do universo simbólico que lhe dá suporte.

Poder-se-ia ainda questionar, a partir de Almeida (2004), se a agroecologia seria um movimento social, pois o agir político-identitário parece surgir apenas ao nível das lideranças das organizações dos agricultores e das ONGs, ou seja, por aqueles que têm maior conhecimento e envolvimento nas "lutas", enquanto muitos agricultores da base sequer reconhecem sua forma de organização e seus princípios. Contudo, não seria esse o sentido de "movimento" e essa impertinência uma característica das "organizações sociais"? O caráter pontual do presente estudo não nos autoriza a dar respostas definitivas.

Viu-se neste trabalho que as organizações, embora tenham um papel importante na mudança de uma realidade convencional para a ecológica, não são os únicos mediadores dessa transição. A experiência subjetiva e intersubjetiva do ator é também um elemento importante. Futuros trabalhos, não só no espaço rural, mas também urbano, podem explorar quais outros elementos auxiliam na transformação ou manutenção de determinada realidade social e contribuem para a ressignificação das identidades sociais dos sujeitos dessas organizações. 


\section{REFERÊNCIAS}

ALMEIDA, J. A construção social de uma nova agricultura: tecnologia agrícola e movimentos sociais no sul do Brasil. Porto Alegre: Ed.Universidade/ UFRGS, 1999.

ALMEIDA, J. Agroecologia: nova ciência, alternativa técnico-produtiva ou movimento social? In: RUSCHEINSKY, A. (Org) Sustentabilidade: uma paixão em movimento. Porto Alegre: Sulina, 2004. p. 88-101.

BAUER, M. A. L; MESQUITA, Z. As concepções de identidade e as relações entre indivíduos e organizações: um olhar sobre a realidade da agricultura ecológica. In: RAC-Eletrônica, v. 1, n. 1, p. 16-30, jan./abr. 2007.

BERGER, P. L. O dossel sagrado: elementos para uma teoria sociológica da religião. São Paulo: Paulus, 1985.

BERGER, P. L.; LUCKMANN, T. A construção social da realidade. 21. ed. Petrópolis: Vozes, 1985.

BOURDIEU, P. A economia das trocas lingüísticas. São Paulo: EDUSP, 1996.

BRUYN, S. La perspectiva humana en sociologia. Buenos Ayres: Amorrortu, 1972.

CAPORAL, F. R; COSTABEBER, J. A. Agroecologia: aproximando conceitos com a noção de sustentabilidade. In: RUSCHEINSKY, A. (Org) Sustentabilidade: uma paixão em movimento. Porto Alegre: Sulina, 2004. p. $46-61$.

CASTELLS, M. O poder da identidade. São Paulo: Paz e Terra, 1999.

CUCHE, D. A noção de cultura nas ciências sociais. Bauru: Edusa, 1999.

DAROLT, M. R. Agricultura orgânica: inventando o futuro. Londrina: IAPAR, 2002.

GOFFMAN, E. Estigma: notas sobre a manipulação da identidade deteriorada. Rio de Janeiro: Guanabara Koogan, 1988.

HABERMAS, J. Teoría de la acción comunicativa. Madrid: Taurus, 1988. t. II.

HABERMAS, J. Racionalidade e comunicação. Lisboa: Edições 70, 1996.

HALL, S. Quem precisa de identidade? In: SILVA, T. T. da (Org) Identidade e diferença: a perspectiva dos estudos culturais. Petrópolis: Vozes, 2000. p. 103-133.

HUSSERL, E. Meditações cartesianas. São Paulo: Madras, 2001.
MARX, K. Manuscritos econômico-filosóficos. São Paulo: Martin Claret, 2005 .

MEAD, G. H. Mind, self and society. Chicago/London: The University of Chicago Press, 1962.

MESQUITA, Z. Do território à consciência territorial. In: MESQUITA, Z; BRANDÃO, Carlos R. (Org) Territórios do cotidiano. Porto Alegre/Santa Cruz do Sul: UFRGS/UNISC, 1995.

MESQUITA, Z.; BAUER, M. A. L. Associativismo em Rede: uma construção identitária em territórios de agricultura familiar. In: Revista Contemporânea de Antropologia e Ciência Política - Antropolítica, v. 17, n. 1, p. 167-189, 2004.

MINAYO, M. C. de S. O desafio do conhecimento. 5. ed. São Paulo: Hucitec; Rio de Janeiro: Abrasco, 1999.

OLIVEIRA, R. C. de Identidade, etnia e estrutura social. São Paulo: Pioneira, 1976.

POBREZA RURAL. Principais transformações econômico-sociais da agricultura brasileira: 1970-1995. In: Impactos das transformações técnico-produtivas sobre a dinâmica demográfica e a qualidade de vida no meio rural do Rio Grande do Sul. Projeto RS 2010, Pobreza Rural, 1998.

REDE ECOVIDA. Rede Ecovida de Agroecologia, 2000. Mimeografado.

SANDERS. P. Phenomenology: a new way of viewing organizational research. In: Academy of Management Review. v. 7, n. 3, p. 353-360, 1982.

SANTOS, M. S. dos. Sobre a autonomia das novas identidades coletivas: alguns problemas teóricos. In: Revista Brasileira de Ciências Sociais, v. 13 , n. 38, p.151-165, 1998.

SELLTIZ, C. e outros. Métodos de pesquisa nas relações sociais. São Paulo: EPU, 1965

SCHUTZ, A. The phenomenology of the social world. Evanston: Northwestern University Press, 1972

SCHUTZ, A. Fenomenologia e relações sociais. In: WAGNER, H. (Org) Textos escolhidos de Alfred Schutz. Rio de Janeiro: Zahar, 1979.

SCHUTZ, A. El problema de la realidad social. 2. ed. Buenos Ayres: Amorrortu, 1995.

SPINK, M. J. P; FREZZA, R. M. Práticas discursivas e produção dos sentidos: a perspective da psicologia social. In: SPINK, M. J. P. (Org) Práticas discursivas e produção de sentidos no cotidiano. 3. ed. São Paulo: Cortez, 2004. 